\title{
Cell Morphological Change and Caspase-3 Protein Expression on Epithelial Cells under Stimulation of Oral Bacterium Streptococcus sanguinis
}

\author{
Suryani Hutomo ${ }^{1}$, Heni Susilowati ${ }^{2}$, Dewi Agustina ${ }^{3}$ \\ ${ }^{1}$ Department of Microbiology, Faculty of Medicine, Duta Wacana Christian University, Jl. Dr. Wahidin Sudiro \\ Husodo 5-25, Yogyakarta 55224, Indonesia \\ ${ }^{2}$ Department of Oral Biology, Faculty of Dentistry, Gadjah Mada University, Jl. Denta, Sekip Utara, \\ Yogyakarta 55281, Indonesia \\ ${ }^{3}$ Department of Oral Medicine, Faculty of Dentistry, Gadjah Mada University, Jl. Denta, Sekip Utara, \\ Yogyakarta 55281, Indonesia \\ Correspondence e-mail to: henisusilowati@ugmac.id
}

\begin{abstract}
Oral commensal bacterium Streptococcus sanguinis may find in periodontal lesions, deep seated infection, and infective endocarditis that are usually dominated by anaerobes. This bacterium caused cell death on some cells but host responses to this species remained unclear. Objective: This study was aimed to detect cell morphological change and role of caspase-3 in cell death mechanism induced by S. sanguinis. Methods: HeLa cells as representative model for oral epithelial cells were exposed to $10^{7}$ cells $/ \mathrm{ml}$ bacteria for $48 \mathrm{~h}$. Morphological change was observed microscopically after hematoxyline-eosin staining. Expression of active caspase-3 was examined by immunocytochemical analysis after cell stimulation for 36 and $48 \mathrm{~h}$ with wild type supragingival S. sanguinis. Doxorubicin $(0.5625 \mu \mathrm{g} / \mathrm{ml})$ was used as positive control for caspase-3 activation. Results: The results showed cell shrinkage of bacterial-treated cells; and active caspase-3 molecules were detected after 36 and 48 hours cell stimulation. Conclusion: This study would suggest cell shrinkage and caspase-3-dependent apoptotic cell death induced by S. sanguinis.
\end{abstract}

Key words: apoptosis; caspase-3 activation, cell shrinkage, Streptococcus sanguinis

\section{INTRODUCTION}

An oral commensal bacterium Streptococcus sanguinis is the earliest species among primary bacterial colony on tooth surface. ${ }^{1}$ This species belongs to viridans groups of streptococci. According to their ability to hemolize red blood cells, this group is classified as $\alpha$-hemolytic bacterium. They partially destroy erythrocytes, causing a greenish discoloration around colonies grown on blood agar. ${ }^{2}$ Streptococcus sanguinis is an aerob-facultative species, but in some cases it can be found in periodontal lesions and deep abscess that are usually dominated by anaerobes. ${ }^{3}$ Streptococcus sanguinis has been known as oral commensal bacteria, but is often implicated in infective endocarditis. Among viridans group streptococci, Streptococcus sanguinis is the most common cause factor of native-valve infective endocarditis. ${ }^{4}$ In addition to the importance of $S$. sanguinis in causing systemic infection, some studies indicated its role in periodontitis. Those studies reported that there are many species associated with the periodontal disease. It was reported that in patients with chronic periodontitis Streptococcus sanguinis was found in 35\% of colonies consisting Prevotella intermedia (37\%), Streptococcus intermedius (36\%), Campylobacter rectus (35\%), and Streptococcus oralis $(34 \%){ }^{5}$ Another study also found that S. sanguinis was detected in the isolate from periodontal pocket in $22.9 \%$ cases of periodontitis patients. ${ }^{6}$ Although $S$. sanguinis was found in periodontal disease, its role in the pathogenesis of periodontal disease still needs to be clarified. 
Sulcular epithelium is the first layer of gingival tissue which functions as barrier to the exposure of dental plaque bacteria. A study on patients with progressive chronic periodontitis revealed that the predominant bacteria in plaque and gingival tissues was viridans streptococci. ${ }^{7}$ As a part of pathobiological mechanism against bacterial exposure, apoptotic cells death were found in the gingival tissue of adult periodontitis patients. A study reported that apoptosis was induced in periodontal tissue by host and microbial factors. The apoptotic cells were found in gingival tissue of patients. ${ }^{3}$ A member of viridans streptococci, $S$. sanguinis had been reported to cause cell death by apoptosis. There was also reported that $S$. sanguinis could induce cell death on lung epithelial cells in rat model. In that study, cell death was characterized by apoptosis as observed microscopically from the nuclear morphological change. ${ }^{8}$ That study demonstrated one of various cellular phenomena of apoptotic cell death induced by $S$. sanguinis. Therefore, a more specific approach for the confirmation of apoptosis in molecular level is necessary.

Induction and execution of apoptosis require cooperation of a series of biomolecules including signal molecules, receptors, enzymes, and genes regulating proteins. Among them are cysteine-dependent aspartate-specific proteases (caspase)-cascade signaling system, which is regulated by various molecules such as inhibitor of apoptosis protein (IAP), Bcl-2 family proteins, and calpain, they are vital in the process of apoptosis. Caspase molecules are synthesized as inactive zymogens, called procaspases. Upon maturation, procaspases are proteolytically processed into the large and small subunits. Proapoptotic caspases can be divided into the group of initiator caspases including procaspases $-2,-8,-9$ and -10 , and that one as executioner caspases including procaspases $-3,-6$, and -7. ${ }^{9}$ Caspase- 3 as a member of executioner caspase can be activated in epithelal cells. There was an elevated expression of caspase-3 in the salivary epithelial cells of Sjögren-Syndrome (SS) patients exposed to specific polyclonal antibodies. It was confirmed that SS salivary epithelial cells underwent apoptosis. ${ }^{10}$ Another study reported that an increasing caspase-3 activity was found in lens epithelial cells exposed with staurosporin. ${ }^{11}$

HeLa cells were used in this study as a model of oral epithelial cells. HeLa cell line is of epithelial origin and it is not cytogenetically identical to oral epithelial cells, but oral bacterial gene expression on invasion of $\mathrm{HeLa}$ cells is similar to what occurs in the mouth. ${ }^{12}$ Antigen expression patterns induced by Aggregatibacter actinomycetemcomitans found in the HeLa cells and gingival epithelial cell line were concurrence. Another study reported that the pili of $S$. sanguinis are involved in bacterial adhesion and invasion on HeLa and human oral epithelial cells surface. ${ }^{13}$ Those evidences suggest that HeLa epithelial cells are appropriate as an in vitro model for oral epithelial cells in their responses to the exposure of oral bacteria.

Streptococcus sanguinis mostly implicated with pathogenesis of infective endocarditis but it can also be found in gingival tissue of adult periodontitis patients. ${ }^{4,6}$ Despite its important role in pathogenesis of systemic infection, its significat action in the pathogenesis of peridontitis is remained unclear. Therefore, the purpose of this study was to identify cell morphological change induced by $S$. sanguinis and to clarify the role of caspase- 3 in cell death mechanism in the HeLa epithelial cells.

\section{METHODS}

\section{Culture of Streptococcus sanguinis}

A dental plaque isolate $S$. sanguinis was obtained from Balai Laboratorium Kesehatan (BLK) Ngadinegaran, Yogyakarta, Indonesia. Streptococcus sanguinis was routinely grown in Brain-Heart Infusion Broth (BHI; Difco Inc., Detroit, MI) supplemented with $1.5 \%$ $(\mathrm{w} / \mathrm{v})$ agar under microaerobic conditions $\left(7.2 \% \mathrm{H}_{2}\right.$, $7.2 \% \mathrm{CO}_{2}, 79.6 \% \mathrm{~N}_{2}$ and $6 \% \mathrm{O}_{2}$ ) in an Anoxomat jar (Spiral Biotech) at $37^{\circ} \mathrm{C}$. Medium was supplemented with kanamycin $\left(500 \mu \mathrm{g} \mathrm{ml}^{-1}\right)$, chloramphenicol $(5 \mathrm{mg}$ $\left.\mu \mathrm{l}^{-1}\right)$, erythromycin $\left(10 \mathrm{mg} \mu^{\mathrm{l}^{-1}}\right)$, and fungisone $0.5 \%$. Bacterial suspension was prepared in concentration of $10^{8}$ cells $/ \mathrm{ml}$ as a stock suspension.

\section{Culture of HeLa cell}

The experiments were done on human epithelial cell line, HeLa cell, that was obtained from Laboratorium Penelitian dan Pengujian Terpadu (LPPT) Unit I, Universitas Gadjah Mada, Yogyakarta. Hela cell line was cultured in RPMI 1640 (Sigma-Aldrich, St Louis, MO, USA) supplemented with 10\% FBS, $100 \mathrm{IU} / \mathrm{ml}$ penicillin and $10 \mu \mathrm{g} / \mathrm{ml}$ streptomycin at $37^{\circ} \mathrm{C}$ in the presence of $5 \% \mathrm{CO}_{2}$. The culture was maintained to get $80 \%$ confluent before harvesting for the experiments. Confluent culture was harvested by using $0.25 \%$ trypsin in PBS. These cells were transferred into 24-well plate for the observation of cell morphological change and detection of active caspase- 3 protein expression.

\section{Cell morphological analysis}

The 24 hours culture of HeLa cells were treated with $10^{7}$ cells/ml S. sanguinis suspension and incubated for another 36 and 48 hours. One group was left untreated as negative control. Morphology of cell was observed under phase contrast microscope after hematoxylineosin (HE) staining.

\section{Detection of active caspase-3}

Immunostaining of active caspase-3 protein was done in Pathology Anatomy Departement, Dr. Sardjito Hospital, Yogyakarta. HeLa cell was cultured in 24 well plate and incubated with RPMI medium for 24 hours. In the following day, the cell was treated with 
$10^{7}$ cells $/ \mathrm{ml}$ bacteria suspension for various incubation times (36, 48 hours). Other groups were cultured with RPMI only as negative control or treated with $0.5625 \mu \mathrm{g} / \mathrm{ml}$ doxorubicin as positive control for 48 hours. After the treatment, the cells were washed with PBS and fixed with methanol. The fixed cells then permeabilized by incubating in methanol for 5 minutes at room temperature followed by three times PBS washing within 5 minutes. The slides were drained and incubated in $200 \mu \mathrm{l}$ of blocking buffer (PBS $+5 \%$ horse serum). The slides were flatted in a humidified chamber and incubated for 2 hours at room temperature, followed by PBS rinsing. Anti-active Caspase-3 antibody (Abcam, Cambrigde, UK) was diluted (1:250) in blocking buffer and were incubated in a humidified chamber overnight at $4^{\circ} \mathrm{C}$. At the following day, the slides were washed twice for 10 minutes in PBS at room temperature, drained, and were exposed to $100 \mu \mathrm{l}$ of 1:250 dilution secondary antibody (Startrek Universal, Promega, Madison, USA). The slides were laid flat in a humidified chamber, protected from light, and incubated for 2 hours at room temperature. Following antibody exposure, the slides were washed twice in PBS for 5 minutes and protected from light. The slides were drained and mounted on glass slide using aqueous mounting medium. Observation was performed under phase contrast microscope to identify and measure the number of caspase-3-positive cells from 10 observation fields. The active caspase- 3 proteins were identified as brown particles in cell cytoplasm or nucleus. Pictures of experiments result were documented at LPPT and Faculty of Biotechnology Duta Wacana Christian University Yogyakarta.

\section{Statistical analysis}

The results obtained from caspase-3 detection experiments were quantified into percent number of caspase-3 expressing cells that was representative data from three times experiments. Normality and homogeneity test were performed using ShapiroWilk and Levene tests, respectively. The statistical analysis showed that those data were homogen and normally distributed with significance value $p>0.05$. The percentage number of caspase- 3 expressing cells was analyzed using One-way Anova. Post Hoc Multiple Comparison was done to analyze mean differences between groups. Statistical significance was determined as $p<0.05$.

\section{RESULTS}

\section{Cell morphological changes induce by Streptococcus sanguinis}

Normal HeLa cells are round or polygonal (Figure 1A), some may showing elongation with cellular processus in monolayer culture (Figure 1B). Observation at 12 hours and 24 hours incubation demonstrated that there was no morphological changes can be observed in those cells (data not shown). Under the stimulation with S. sanguinis whole cell, HeLa cell morphology was change. That alteration was observed in cell shape and size; as shown in Figure 1C and 1E. In general, the cell shape changed to round with large spherical nucleus after bacterial exposure. Cytoplasmic processus disappeared, causing smaller cell apearance in most of cell population. The ratio of cytoplasm and nucleus was decreased in bacteria-treated cells.

Cell morphological changes appeared at $36 \mathrm{~h}$ after treatment with $S$. sanguinis. The results demonstrated shrinkage cells and loose of intercellular contact compared to the normal cells. Cellular damage was observed as rounded cell characterized by high intensity color under HE staining. The cell nuclei were dark as a result of its capability to absorb the hematoxylin dye. After $48 \mathrm{~h}$ treatment, there was increased number of damage cells than they were at $36 \mathrm{~h}$ (unpublished data). The cell morphological change as confirmed in this study indicated that $S$. sanguinis could induce irreversible damage in HeLa cells. Those morphological alterations indicated cell damage leading to die. We investigated a part of molecular activation that may play as an important key in these cell death mechanism by detection of caspase- 3 activation.

\section{Caspase-3 activation under stimulation of Streptococcus sanguinis}

This study demostrated that treatment of HeLa cells with S.sanguinis whole cell induced expression of active caspase- 3 protein. This phenomenon was detected from $36 \mathrm{~h}$ after treatment and showed increased intensity of expression after 48 h (Fig. 2).

The expression of active caspase-3 was indicated by brown particles (in full color picture) resided in cell cytoplasm (Figure 2). The expression of active caspase-3 indicated apoptotic cell death induced by $S$. sanguinis. The brown particles were found $36 \mathrm{~h}$ after S.sanguinis exposure to HeLa cells. As shown in Figure $2 \mathrm{E}$, the caspase- 3 protein expression was still remain, and increased after $48 \mathrm{~h}$ cell exposure with S.sanguinis. There was no doubt that protein expression on HeLa cells was induced by bacterial exposure since caspase-3 particles were not detected in resting cells as shown in control groups.

The results obtained from caspase-3 detection experiments were quantified into percentage of caspase-3-expressing cells to that cell population number counted in 10 different observation area. The results were summarized in the following table.

Table 1 shows number of caspase-3-expressing cells among three groups. There were increased number of active caspase-3-expressing cells after treatment with S.sanguinis for $36 \mathrm{~h}$. The number of caspase3 -expressing cells was higher in the group treated with S.sanguinis for $48 \mathrm{~h}$. As for statistical analysis, 


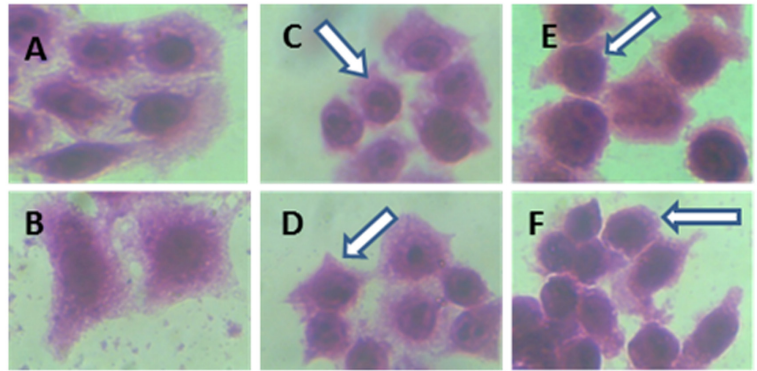

Figure 1. Exposure of HeLa cells with $S$. sanguinis (40x magnification). Untreated cells were incubated for $36 \mathrm{~h}(\mathrm{~A})$ and $48 \mathrm{~h}$ (B). Thirty six hours exposure with $S$. sanguinis (C) or Doxorubicin (D) resulted in cell shrinkage. The number of cell undergone shrinkage was increased after $48 \mathrm{~h}$ treatment with S.sanguinis (E) or Doxorubicin (F).
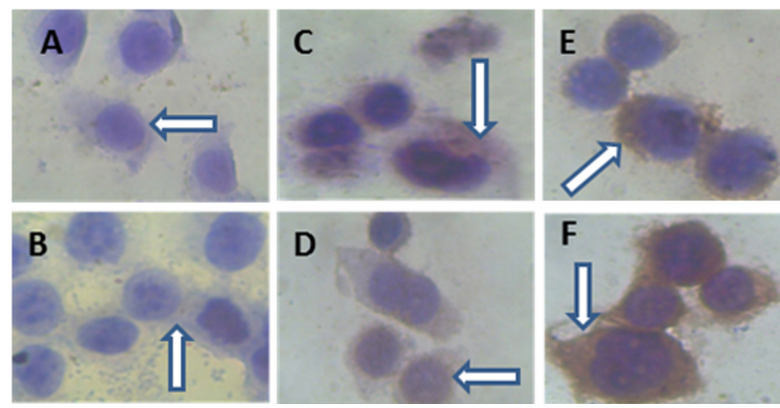

Figure 2. Active caspase-3 expression in HeLa cells (40x magnification). Untreated cells within $36 \mathrm{~h}$ (A) and $48 \mathrm{~h}$ (B) culture, appeared as clear either cytoplasm or nuclear area. Cells treated with S.sanguinis (C) or Doxorubicin (D) for $36 \mathrm{~h}$ demonstrated activation of caspase-3 protein as shown in brown color particles in cell cytoplasm (arrow). The expression of active caspase-3 was increased after 48 $\mathrm{h}$ treatment either with S.sanguinis (E) or Doxorubicin (F).

Shapiro-Wilk test was used to analyze normality of the data. The $p$ value for control, $36 \mathrm{~h}$ stimulation, and 48 $\mathrm{h}$ stimulation respectivelly were $0.075 ; 0.869 ; 0.596$, and $48 \mathrm{~h}$. Those $p$ value indicated that the data were distributed normally. In further step, Levene test was used to examine homogeneity of the data. The $p$ value for all data based on mean, median, trimmed mean and adjusted df were $0.051 ; 0.082 ; 0.130 ; 0.054$, these meant that they were homogen.

For testing the effect of bacterial treatment on caspase expression, One-Way ANOVA was run to compare means between four groups (36h control, $48 \mathrm{~h}$ control, $36 \mathrm{~h}$ and $48 \mathrm{~h}$ treatment) at significance level of 0.05 . There was significant difference in percentage of caspase-3 activation between controls and treatment groups. It was confirmed that treatment of HeLa cells with $S$. sanguinis could induce increased expression of active caspase-3. Furthermore, Post Hoc Test (Bonferroni and Scheffe) was done to analyze mean differences between groups. The results of this analysis showed at Table 2.
Table 1. Means and standard deviations of percentage of caspase-3-expressing HeLa cells after $S$. sanguinis exposure

\begin{tabular}{|c|c|c|c|c|}
\hline \multirow{2}{*}{ Groups } & \multicolumn{2}{|c|}{ Negative Control } & \multicolumn{2}{|c|}{ S.sanguinis-treated cells } \\
\hline & 36 hours & 48 hours & 36 hours & 48 hours \\
\hline $\begin{array}{l}\text { Mean } \\
\text { percentage } \\
\text { of active } \\
\text { caspase-3 } \\
\text { expressing } \\
\text { cells }\end{array}$ & $0.123 \pm 0.136$ & $0.405 \pm 0.188$ & $8.607 \pm 0.918$ & $29.345 \pm 0.846$ \\
\hline
\end{tabular}

The data were representative value from three times experiments.

Table 2. Summary of Post Hoc Multiple Comparison Test to percentage of acitive caspase-3-expressing cells

\begin{tabular}{lcccccc}
\hline \multirow{2}{*}{ Groups } & Time & \multicolumn{2}{c}{ Control groups } & \multicolumn{2}{c}{ Treatment groups } \\
\cline { 3 - 7 } & & $36 \mathrm{~h}$ & $48 \mathrm{~h}$ & $36 \mathrm{~h}$ & $48 \mathrm{~h}$ \\
\hline \multirow{2}{*}{ Control groups } & $36 \mathrm{~h}$ & - & & & \\
& $48 \mathrm{~h}$ & 1.000 & - & & \\
\multirow{2}{*}{ Treament groups } & $36 \mathrm{~h}$ & $0.000^{*}$ & $0.000^{*}$ & - & \\
& $48 \mathrm{~h}$ & $0.000^{*}$ & $0.000^{*}$ & $0.000^{*}$ & - \\
\hline
\end{tabular}

*Significant at $p<0.05$

As summarized in Table 2, there was no significant difference in caspase-3 expression between control groups. Differences were identified between control groups (36 and 48 hours) and treatment groups; as well as between treatment groups. The data showed that the longer exposure time, the higher increased caspase-3 expression.

\section{DISCUSSION}

This study confirmed that oral commensal bacterium S. sanguinis could cause cell damage leading to death on HeLa cells. Cellular shrinkage was detected in S. sanguinis-treated HeLa cells after 36 hours, and majority of the cell populations have undergone shrinkage after 48 hours incubation with $S$. sanguinis. The damaged cells appeared as round or oval masses with dark eosinophilic cytoplasm with dense purple nuclear chromatin. The cells appeared in smaller sizes, and had lost contact with neighboring cells. These phenomena suggesting irrevesible cellular damage leading to death. Cell death induced by S.sanguinis also found in human macrophage cell line (THP-1). That cell generate death mechanism which is independent of caspase activation; it was caused by increase of reactive oxygen species (ROS). ${ }^{14}$ Previous study on Streptotoccus pneumoniae and S. sanguinis revealed that those bacteria were able to induce apoptotic cell death on lung cells of rat model, although they run in different patern of death mechanisms. ${ }^{8}$ 
Molecular background may explain cell morphological alteration. In this study, active caspase- 3 proteins were detected in the cytoplasm of S. sanguinis-treated HeLa cells. Since caspase-3 functions as executioner enzyme in apoptotic cell death, ${ }^{9}$ it is believed that HeLa cell death caused by $S$. sanguinis was apoptosis (caspasedependent programmed cell death). Apoptosis is a vital mechanism in wound healing processes. It functions are to drive regeneration processes of granulation tissue to minimize scar tissue formation. ${ }^{15}$ In this study, we can see that even in control group, some cells also died after $36 \mathrm{~h}$ culture. It was in line with previous theory that if not apoptosis, then at least cell death, can be found not only in pathologic condition, but also in physiologic condition. Physiologically, apoptosis also occurs in immune system. More than $95 \%$ of B-cells and T-cells die during maturation process. In addition, apoptosis also important for removal of infected and damage cells, morphogenetic changes during embryonic development, and tissue homeostasis..$^{16}$ On the other hand, in pathophysiological conditions apoptosis contributes in mechanisms to prevent host tissue from exposure of pathogens. In this case, infected cells are removed from the body by apoptosis, followed by phagocytosis by macrophage.

Caspase-3 is known as a key factor in apoptosis execution. This molecule is activated in cytosol, closed to the surface of cellular membrane, and then transfered to the cytoplasm. ${ }^{17}$ Active caspase-3 enters nucleus through nuclear membrane pores which is generated by caspase- 9 activation, releasing apoptotic substrates that able to cause DNA degradation. Another molecular phenomenon caused by activation of caspase- 3 is cleavage of nuclear skeleton components, lamin and fodrin. The cleavage of lamin by caspases-3 can cause chromatin condensation and decomposition of nuclear membrane. Furthermore, cleavage of fodrin could induce apoptotic body formation. ${ }^{9}$ There is closed relatioship between caspase-3 activation and cell morphological changes. Caspase-3 activation can cause protein and kinases cleavage, membrane externalization, cytoplasm and nuclear condensation. ${ }^{17}$

It is assumed that the mechanism of apoptotic cell death induced by $S$. sanguinis can be conducted in different mechanisms. One possible mechanism may be involves hydrogen peroxide $\left(\mathrm{H}_{2} \mathrm{O}_{2}\right)$ production. Like other Streptococci, S. sanguinis is able to produce $\mathrm{H}_{2} \mathrm{O}_{2} \cdot{ }^{18}$ The $\mathrm{H}_{2} \mathrm{O}_{2}$ production by Streptococci may act as potential virulence factor that causes direct damages to the host tissues. In case of another species, $\mathrm{H}_{2} \mathrm{O}_{2}$ produced by $S$. pyogenes can cause damages to host tissues directly. ${ }^{19}$ Another scenario is that $\mathrm{H}_{2} \mathrm{O}_{2}$ produced by $S$. pnemoniae induced apoptosis-like cellular response. ${ }^{20}$ A study on mucosal epithelial cells reported that $\mathrm{H}_{2} \mathrm{O}_{2}$ produced by bacterial origins could cause apoptosis. ${ }^{21}$ $\mathrm{H}_{2} \mathrm{O}_{2}$ induced apoptosis in HeLa cells was regulated by simultaneous activations of pro-apoptotic p73, Bax and inhibitions of anti-apoptotic Bcl-XL. It will be followed by the release of cytochrome $\mathrm{c}$ and the activation of caspase-9 and caspase-3. It was the intrinsic apoptotic pathway. ${ }^{22}$ The production of $\mathrm{H}_{2} \mathrm{O}_{2}$ in $S$. sanguinis may cause release of extracelluler DNA (eDNA). Recently it is known that eDNA produced by bacteria is necessary for the development of biofilm and cell-cell adhesion. ${ }^{1,}$ ${ }^{23}$ It has serious implication to cellular homeostasis of host cells because once the bacteria release $\mathrm{H}_{2} \mathrm{O}_{2}$, it will induce the production of eDNA to promote biofilm formation and cell-cell adhesion.

Another possible mechanism is induction of apoptosis by activation of inflammatory mediator interleukin-8 (IL-8). Molecular signal generated by IL-8 may induce the activation of extrinsic apoptosis pathway by transcription-mediated increases in c-FLIP expressions on prostate cancer cells. ${ }^{24}$ IL- 8 was produced by oral epithelial cells under stimulation of multispecies microbial biofilm including $S$. sanguinis. ${ }^{25}$ In case of bacterial infection, it was reported that there was secretion of IL-8 following the infection of $S$. gordonii within $4 \mathrm{~h}$ stimulation. Streptococcus sanguinis and $S$. pneumoniae also can cause apoptosis. ${ }^{26}$ Another study revealed that those bacteria induced apoptosis in lung cells. ${ }^{8}$ Those studies indicated that IL-8 produced by $S$. sanguinis could be one of the possible substances that can cause HeLa cell death. Therefore, the apoptosis induced by $S$. sanguinis could happen by means of intrinsic and extrinsic pathways.

Although there were two possible mechanisms of apoptosis, this report demonstrated that the apoptosis in HeLa cells induced by $S$. sanguinis probably happened by extrinsic pathway. It was shown from the fact that active caspase- 3 was detected in HeLa cells predominantly. Interleukin-8 (IL-8) from HeLa epithelial cells stimulated by $S$. sanguinis might be induced the activation of the extrinsic apoptosis pathway. On the other hand, $\mathrm{H}_{2} \mathrm{O}_{2}$ produced by $S$. sanguinis in aerobic condition was probably degraded into $\mathrm{H}_{2} \mathrm{O}$ and $\mathrm{O}_{2}$ immediately. As a result, $\mathrm{H}_{2} \mathrm{O}_{2}$ produced by $S$. sanguinis probably was not strong enough to induce apoptosis on HeLa cells.

The role of $S$. sanguinis in the pathogenesis of periodontal disease is still unclear. A study conducted on patients with progressive chronic periodontitis found that the predominant bacterium in plaque and gingival tissue was Viridans streptococci. ${ }^{7}$ Colombo et al. also reported that in patients with chronic periodontitis, S.sanguinis was found in $35 \%$ of the colonies. ${ }^{5}$ In the mouth, S.sanguinis is known as oral commensal bacteria. When these bacteria enter systemic compartments like the blood circulation, they will express environmentally regulated genes to adapt with the new environment. This gene expression is regulated by many factors like the changes in $\mathrm{pH}$, oxygen level or temperature. For example, at $\mathrm{pH} 6.5$ 
to 7, oral Streptococci release a histone-like protein (HlpA) into the medium. At $\mathrm{pH}$ below 6, this protein is disapear. Histone-like protein binds to a soluble lipoteichoic acid, a major constituent of outer envelope of gram-positive bacteria. The complexities will be able to be recognized by specific antibody resulting in inflammations and the increase of the bacteria's pathogenicity. Stressor from new environment can modify the bacterial nature become more virulent. ${ }^{27}$ Another oral commensal bacterium, $S$. intermedius, is also associated with suppurative infections. It also has the tendency to cause abscess formations commonly found in the liver and the brain. ${ }^{28}$. This species produces intermedilysin (ILY), a human-specific cytotoxin, which would become higher in its production while the species is found in anaerobic situation, an deepseated abscess. ${ }^{29}$

One important point that can be deduced from this study is although S.sanguinis is known as oral commensal bacteria, in certain conditions it may change into pathogenic bacteria. To survive in its foreign environment, $S$. sanguinis usually stays in an abnormal or injured anatomic site, or an immunocompromised host. ${ }^{27}$ Streptococcus sanguinis colonizing the heart valves causes a systemic infection called the infective endocarditis. The mortality in endocarditis varies between $4-14 \% .{ }^{30}$ Finally, our results suggested that oral commensal bacteria need more awareness regarding its ability to injure oral or systemic tissues, especially in immunocompromised patients. The apoptosis induced by S. sanguinis might happen by means of intrinsic and extrinsic pathways. In this study, there has not been cleared yet which part of $S$. sanguinis that can cause the apoptosis in HeLa cells; that is why it needs to be clarify in further study.

\section{CONCLUSION}

From the results of this study it is concluded that Streptococcus sanguinis could induce alteration of cell morphology, notified by cellular shrinkage on HeLa cells, and caspase-3 may play important role in cell death mechanism.

\section{ACKNOWLEDGEMENT}

Authors would like to thank all technicians in Laboratorium Pengembangan dan Penelitian Terpadu (LPPT) UGM and Anatomic Pathology Laboratory, dr Sardjito Hospital Yogyakarta.

\section{REFERENCES}

1. Kreth J, Zhang Y, Herzberg MC. Streptococcal antagonism in oral biofilms: Streptococcus sanguinis and Streptococcus gordonii interference with Streptococcus mutans. J Bacteriol 2008;190:4632-40.

2. Murray PR, Rosenthal KS, Pfaller MA. Medical Microbilogy. 6th ed. Mosby Elsevier. 2009.

3. Gamonal J, Bascones A, Acevedo A, Blanco E, Silva A. Apoptosis in chronic adult periodontitis analyzed by in situ DNA breaks, electron microscopy, and immunohistochemistry. J Periodontol. 2001;72:517-25.

4. Ge X, Kitte T, Chen Z, Lee SP, Munro CL. Xu P. Identification of Streptococcus sanguinis genes required for biofilm formation and examination of their role in endocarditis virulence. Infect Immun. 2008;76:2551-9.

5. Colombo AV, Silva CM, Haffajee A. Identification of oral bacteria associated with crevicular epithelial cells from chronic periodontitis lesions. J Med Microbiol. 2006;55: 609-15.

6. Maestre JR, Bascones A, Sanchez P, et al. Odontogenic bacteria in periodontal disease and resistance patterns to common antibiotics used as treatment and prophylaxis in odontology in Spain. Rev Esp Quimioter, 2007;20:61-7.

7. Vitkov L, Hannig M, Krautgartner WD, Fuchs K. Bacterial adhesion to sulcular epithelium in periodontitis. FEMS Microbiol Lett. 2002;211:23946.

8. Kazzaz JA, Horowitz S, Xu J, et al. Differential paterns of apoptosis in resolving and nonresolving bacterial pneumonia. Am J Respir Crit Care Med. 2000;161:2043-50.

9. Fan TJ, Han LH, Cong RS, Liang J. Caspase family proteases and apoptosis. Acta Biochim Biophys Sin (Shanghai). 2005;37: 719-27.

10. Jimenez F, Aiba-Masago A, Al Hashimi I, et al. Activated caspase 3 and cleaved poly(ADPribose)polymerase in salivary epithelium suggest a pathogenic mechanism for Sjögren's-syndrome. Rheumatol. 2002;41:338-42.

11. Andersson M, Sjőstrand J, Petersen A, Honarvar AK, Karlsson JO. Caspase and proteasome activity during staurosporin-induced apoptosis in lens epithelial cells. Invest Ophthalmol Vis Sci. 2000;41:2623-32.

12. Richardson J, Craighead JC, Cao SL, Handfield M. Concurrence between the gene expression pattern of Actinobacillus actinomycetemcomitans in localized aggressive periodontitis and in human epithelial cells. J Med Microbiol 2005;54:497-504

13. Okahashi N, Nakata M, Sakurai A, et al. Pili of oral Streptococcus sanguinis bind to fibronectin and contribute to cell adhesion. Biochem Biophys Res Commun 2010;391:1192-1206.

14. Okahashi N, Nakata M, Terao Y, et al. Pili of oral Streptococcus sanguinis bind to salivary amylase 
and promote the biofilm formation. Microb Pathog. 2011;50:148-54.

15. Elmore S. Apoptosis : A review of programmed cell death. Toxicol Pathol. 2007;35: 495-516.

16. Porth CM, Matfin G. Pathophysiology. Concepts of Altered Health States. 8th ed. Lippincott Williams \& Wilkins. Philadelphia. USA. 2009.

17. Feng Y, Hu J, Xie D, et a. 2005. Subcellular localiation of caspase-3activation correlateswith changes in apoptotic morphology in MOLT-4 leukemia cells exosed to X-ray irradiation. Int J Oncol. 2005;27:699-704.

18. Uehara Y, Agematsu, Kikuchi K, et al. Secretory IgA, salivary peroxidase, and catalase-mediated microbicidal activity during hydrogen peroxide catabolism in viridians streptococci: pathogen coaggregation. J Infect Dis 2006;194:98-107.

19. Ginsburg I, Sadovnic M. Gamma globulin, Evan's blue, aprotinin A PLA2 inhibitor, tetracycline and antioxidants protect epithelial cells against damage induced by synergism among streptococcal hemolysins, oxidants and proteinases: relation to the prevention of post-streptococcal sequelae and septic shock. FEMS Immunol Med Microbiol. 1998;22:247-56.

20. Regev-Yochay GK, Trzcinski CM, Thompson M, Lipsitch M, Malley R. SpxB is a suicide gene of Streptococcus pneumoniae and confers a selective advantage in an in vivo competitive colonization model. J Bacteriol. 2007;189:6532-9.

21. Strus M, Janczyk A, Gonet-Surowka A, et al. Effect of hydrogen peroxide of bacterial origin on apoptosis and necrosis of gut mucosa epithelial cells as a possible pathomechanism of inflammatory bowel disease and cancer. J Physiol Pharmacol. 2009; Suppl 6:55-60.
22. Singh M, Sharma H, Singh N. Hydrogen peroxide induces apoptosis in HeLa cells through mitochondrial pathway. Mitochondrion. 2007;7:367-73.

23. Kerth J, Vu H, Zhang Y, Herzberg MC. Characterization of hydrogen peroxide-induced DNA release by Streptococcus sanguinis and Streptococcus gordonii. J Bacteriol. 2009;191:628191.

24. Wilson C, Wilson T, Johnston PG, Longley DB, Waugh DJ. Interleukin-8 signaling attenuates TRAIL- and chemotherapy induced apoptosis through transcriptional regulation of c-FLIP in prostate cancer cells. Mol Cancer Ther. 2008;7: $2649-61$.

25. Peyyala R, Kirakodu SS, Novak KF, Ebersole JL: Oral Epithelial cell responses to multispecies microbial biofilms. J Dent Res. 2013;92:235-40.

26. Hasegawa Y, Mans JJ, Mao S, et al. Gingival epithelial cell transcriptional responses to commensal and opportunistic oral microbial species. Infect. Immun. 2007;75:2540-47.

27. Lamont RJ, Burne RA, Lantz MS, LeBlanc DJ. Oral Microbiology and Immunology. ASM Press,Washington DC. 2006.

28. Summanen PH, Rowlinson MC, Wooton J, Finegold SM. Evaluation of genotypic and phenotypic methods for differentiation of members of the anginosus group streptococci. Eur J Clin Microbiol Infect. 2009;8:1123-8.

29. Sukeno A, Nagamune H, Whiley RA, et al. Intermedilysin is essential for the invasion of hepatoma HepG2 cells by Streptococcus intermedius. Microbiol Immunol. 2005;49:681-94.

30. Westling K. Viridans group Streptococci septicaemia and endocarditis. Karolinka Instituted, Stockholm. 2005.

(Received November 22, 2014; Accepted May 11, 2015) 